\title{
What do patients consulting in a free sexual health center know about HIV transmission and post-exposure prophylaxis?
}

Christelle Duteil $^{1 *}$ (D) Elise de La Rochebrochard ${ }^{2,3}$, Prescillia Piron ${ }^{1,4}$, Christophe Segouin ${ }^{1,4}$ and Pénélope Troude ${ }^{1,2}$

\begin{abstract}
Background: Screening, condom use and post-exposure prophylaxis (PEP) are among existing HIV prevention strategies. However, efficient use of these strategies requires that patients have an adequate knowledge of HIV transmission routes and awareness of risk behaviors. This study aimed to assess knowledge about HIV transmission among patients who attended a free HIV and sexually transmitted infection (STI) screening center in Paris, France, and to explore the patient profiles associated with HIV-related knowledge.
\end{abstract}

Methods: This observational cross-sectional study included 2002 patients who attended for STI testing from August 2017 through August 2018 and completed a self-administered electronic questionnaire. Based on incorrect answers regarding HIV transmission, two outcomes were assessed: lack of knowledge and false beliefs. Factors associated with these two outcomes were explored using univariate and multivariate logistic regressions.

Results: Only 3.6\% of patients did not know about HIV transmission through unprotected sexual intercourse and/or by sharing needles. More than one third of patients (36.4\%) had at least one false belief, believing that HIV could be transmitted by sharing a drink (9.7\%), kissing (17.6\%) or using public toilets (27.5\%). A low educational level and no previous HIV testing were associated in multivariate analyses with both lack of knowledge and false beliefs. Age and sexual orientation were also associated with false beliefs. Furthermore, 55.6\% of patients did not know that post-exposure prophylaxis consists of taking emergency treatment as soon as possible after risky intercourse.

Conclusions: Although the main HIV transmission routes are well known, false beliefs persist and knowledge regarding PEP needs to be improved. Prevention campaigns must focus on these themes which appear as a complementary strategy to pre-exposure prophylaxis to reduce HIV infection.

Keywords: HIV, Knowledge, False beliefs, Free HIV and sexually transmitted infection screening center, Postexposure prophylaxis

\footnotetext{
* Correspondence: christelle.duteil@aphp.fr

'Service de Santé Publique, Hôpitaux Lariboisière - Fernand-Widal, AP-HP Nord, F-75010 Paris, France

Full list of author information is available at the end of the article
}

(c) The Author(s). 2021 Open Access This article is licensed under a Creative Commons Attribution 4.0 International License, which permits use, sharing, adaptation, distribution and reproduction in any medium or format, as long as you give appropriate credit to the original author(s) and the source, provide a link to the Creative Commons licence, and indicate if changes were made. The images or other third party material in this article are included in the article's Creative Commons licence, unless indicated otherwise in a credit line to the material. If material is not included in the article's Creative Commons licence and your intended use is not permitted by statutory regulation or exceeds the permitted use, you will need to obtain permission directly from the copyright holder. To view a copy of this licence, visit http://creativecommons.org/licenses/by/4.0/. The Creative Commons Public Domain Dedication waiver (http://creativecommons.org/publicdomain/zero/1.0/) applies to the data made available in this article, unless otherwise stated in a credit line to the data. 


\section{Background}

Human immunodeficiency virus (HIV) remains a public health challenge worldwide. An estimated 37.9 million people were living with HIV and nearly 1.7 million people were newly infected in 2018 [1]. Almost two thirds of new HIV infections were observed in Africa, with 800,000 new infections in Eastern and Southern Africa in 2018. However, HIV also remained a public health issue in high-income countries, as 68,000 new infections were estimated in Western and Central Europe and in North America in 2018 [2]. With 6200 new infections, France is one of the Western countries most affected by HIV [3]. Despite facilitated access to HIV care, late-stage diagnosis represents a third of new HIV diagnoses in France and half of these new diagnoses concerned people who had never been tested before [4]. HIV prevention strategies that include screening, condom use, needle exchange programs, treatment of sexual transmitted infections and also treatment as prevention (TasP), post-exposure prophylaxis (PEP) and preexposure prophylaxis (PrEP) are needed to reduce the epidemic [5]. However, if they are to be effective, people must be aware of these strategies. For instance, a minimum of knowledge is needed for efficient use of PEP as it is an emergency treatment that must be taken as soon as possible and within $48-72 \mathrm{~h}$ (48 $\mathrm{h}$ in France) after potential exposure to HIV to reduce the risk of becoming seropositive. Use of PEP therefore requires knowledge of HIV transmission routes and awareness of risk behaviors.

Despite decades of public health information policies, knowledge about HIV may in fact have decreased, particularly among young people. According to the last national surveys in France, between 1994 and 2010 there has been a decrease in prevention practices, a decline in the level of HIV risk perception and an increase in erroneous beliefs regarding HIV transmission among young adults (18-29 years) [6]. Studies from other countries have underlined sexual risk behaviors and lack of HIV knowledge among young students, supporting the need for preventive and informative campaigns at earlier stages of adolescence [7-10]. Although most recent studies have focused on young people (college and university students), lack of HIV knowledge may also affect older people [11]. Some studies have also reported an association between HIV knowledge and factors such as sexual orientation, previous HIV testing or unprotected sexual intercourse [7, 12-16].

In France, screening centers for HIV and sexually transmitted infections (STIs) provide free and anonymous screening in order to reach socially disadvantaged and high-risk populations. Since 2016, the mission of these centers has expanded to address overall sexual health. Patients' visits to screening centers provide opportunities to spread sexual health messages and to provide individual information about sexual risk behaviors [17]. HIV voluntary counseling and testing (HCT) recipients were significantly less likely to have unprotected sexual intercourse after than before HCT, or compared with participants who had not received HCT [17].

This study aimed to assess the level of knowledge regarding HIV transmission of patients who attended a free HIV and STI screening center and to explore the patient profiles associated with HIV knowledge.

\section{Methods \\ Setting}

This cross-sectional observational study was conducted in a free HIV and STI screening center in a Paris hospital (Fernand-Widal Hospital). The center offers tests for HIV, HBV, HCV, syphilis, chlamydia and gonorrhea. Since August 2017, every new patient who understands written French is invited by the reception agent to complete an optional and anonymous electronic selfadministered questionnaire. Patients complete the questionnaire prior to medical consultation on a dedicated computer in a private area in the waiting room.

\section{Study population}

From August 2017 through August 2018, 3589 patients visited the screening center for HIV or other STI testing. We excluded from the study population patients younger than 18 or older than 54 years $(n=223)$ and those who did not understand written French $(n=$ 304). Of the 3062 eligible patients, 2002 completed the self-administered questionnaire and were included in the study.

\section{Data collection}

Data were obtained from the consultation database and the self-administered questionnaire. The consultation database contained date of consultation, gender, year of birth, STIs tested, test results, and date of return for results. The self-administered questionnaire (see Additional file 1) included three sets of variables: sociodemographic data, sexual behaviors or practices, and knowledge or beliefs regarding HIV transmission routes and prevention. Firstly, it included sociodemographic data: year of birth, gender, nationality, work status, educational level and health insurance coverage. Secondly, it included sexual behaviors and practices: gender of sexual partner(s), previous HIV testing, and having at least one act of unprotected sexual intercourse with partner(s) of unknown HIV status since the last HIV testing or ever. Sexual orientation was defined as a fourcategory variable: men who have sex with men (MSM), men who have sex exclusively with women, women who have sex with women (WSW) and women who have sex 
exclusively with men. Finally, the questionnaire included true and false statements to assess the level of knowledge regarding HIV transmission and post-exposure prophylaxis. For each statement, patients had the option of choosing "yes", "no", or "don't know". Participants who answered "don't know" were grouped with the incorrectly answers. Knowledge was assessed by two questions related to true HIV transmission routes (the correct answer was "yes"): having unprotected sexual intercourse and sharing used needles. False beliefs regarding HIV were assessed by three questions related to false HIV transmission routes (the correct answer was "no"): sharing a drink with an infected person, kissing an infected person, and using public toilets.

\section{Statistical analysis}

First, sociodemographic data, sexual and prevention practices of the study population were described. We also detailed answers to statements regarding HIV transmission routes and PEP to fulfill our primary goal. Then, to fulfill our secondary goal, i.e. to explore factors associated with knowledge level, two outcomes were considered. First, a lack of knowledge of HIV transmission routes was defined as giving at least one incorrect answer to the two questions on true modes of HIV transmission ("unprotected sexual intercourse" and "sharing used needles"). Secondly, having false beliefs on HIV transmission was defined as giving at least one incorrect answer to the three questions on false HIV transmission routes (sharing a drink with an infected person, kissing an infected person, and using public toilets).

Factors associated with each of the two outcomes were studied using univariate and multivariate logistic regression models. Because of the small numbers of events, we adopted a parsimonious methodology for multivariate analyses. For each studied outcome, multivariate models included factors selected by a stepwise backward selection method with a threshold of 0.2 for removal from the model. Associations were considered as statistically significant when $p<0.05$. Statistical analyses were performed using STATA/SE 13.1 (Stata Corporation, College Station, TX, USA).

\section{Results}

\section{Description of the study population}

Of the 3062 eligible patients, 2002 completed the questionnaire and were included in the present study (participation rate 65\%). The characteristics of the study population are presented in Table $1(n=2002)$. Two thirds of patients were men $(65.6 \%)$ and nearly half (45.5\%) were $25-34$ years old. Half of the study population was employed (52.3\%), one third was in training (33.7\%) and most patients had at least a high school diploma (91.0\%). A minority declared they had no health
Table 1 Sociodemographic characteristics of the study population and sexual and prevention practices $(n=2002)$

\begin{tabular}{|c|c|c|}
\hline & $\mathbf{n}$ & $\%$ \\
\hline \multicolumn{3}{|l|}{ Age (years) } \\
\hline $18-24$ & 716 & 35.8 \\
\hline $25-34$ & 912 & 45.5 \\
\hline $35-54$ & 374 & 18.7 \\
\hline \multicolumn{3}{|l|}{ Gender } \\
\hline Men & 1314 & 65.6 \\
\hline Women & 688 & 34.4 \\
\hline \multicolumn{3}{|l|}{ French nationality } \\
\hline Yes & 1752 & 87.5 \\
\hline No & 250 & 12.5 \\
\hline \multicolumn{3}{|l|}{ Activity status } \\
\hline Employed & 1052 & 52.5 \\
\hline Student/Training & 677 & 33.8 \\
\hline Unemployed & 273 & 13.6 \\
\hline \multicolumn{3}{|l|}{ Educational level } \\
\hline$<$ High school diploma & 161 & 8.0 \\
\hline High school diploma & 456 & 22.8 \\
\hline > High school diploma & 1385 & 69.2 \\
\hline \multicolumn{3}{|l|}{ Health insurance coverage } \\
\hline Yes & 1822 & 91.0 \\
\hline No & 180 & 9.0 \\
\hline \multicolumn{3}{|l|}{ Sexual orientation } \\
\hline Men who have sex exclusively with women & 892 & 44.5 \\
\hline Men who have sex with men & 422 & 21.1 \\
\hline Women who have sex exclusively with men & 594 & 29.7 \\
\hline Women who have sex with women & 94 & 4.7 \\
\hline \multicolumn{3}{|l|}{ Previous HIV testing } \\
\hline None & 443 & 22.1 \\
\hline Yes, one & 490 & 24.5 \\
\hline Yes, several & 1069 & 53.4 \\
\hline \multicolumn{3}{|l|}{ At least one positive result } \\
\hline Yes & 204 & 10.2 \\
\hline No & 1798 & 89.8 \\
\hline
\end{tabular}

At least one act of unprotected sexual intercourse with a partner of unknown HIV status

\begin{tabular}{lll} 
Yes & 603 & 30.1 \\
No & 1399 & 69.9 \\
\hline
\end{tabular}

insurance coverage (9.0\%). Almost one third (30.1\%) had had at least one act of unprotected sexual intercourse with a person of unknown HIV status. More than three quarters of the study population had already been tested for HIV (77.9\%). Regarding screening results, $10.2 \%$ of patients had at least one positive result 
and the infection most frequently tested was chlamydia (see Additional file 2).

\section{Level of knowledge and false beliefs regarding HIV transmission and level of knowledge on post-exposure treatment}

HIV knowledge is presented in Table 2. Only $1.2 \%$ of the study population [95\% CI, 0.7 to 1.7] did not know that HIV transmission is possible through unprotected sexual intercourse and 3.3\% [95\% CI, 2.5 to 4.1] through sharing used needles. In summary, 3.6\% [95\% CI, 2.8 to 4.4] of the study population had a lack of knowledge of $H I V$ transmission routes (i.e they had given an incorrect answer to at least one of the two items). Concerning false HIV transmission routes, 9.7\% [95\% CI, 8.4 to 11.0] believed that HIV transmission is possible by sharing a drink with an infected person, 17.6\% [95\% CI, 15.9 to 19.3] by kissing an infected person and $27.5 \%$ [95\% CI, 25.5 to 29.4 ] by using public toilets. In summary, more than one third of the study population, 36.4\% [95\% CI, 34.3 to 38.5 ] had false beliefs on HIV transmission (i.e they had given an incorrect answer to at least one of the three items). Furthermore, 55.6\% [95\% CI, 53.4 to 57.7] of the study population did not know that post-exposure prophylaxis consists of taking emergency treatment as soon as possible after risky intercourse.

\section{Factors associated with lack of knowledge and with false beliefs}

Table 3 presents univariate and multivariate regression models for each outcome studied: 1) lack of knowledge of HIV transmission routes and 2) false beliefs on HIV transmission.

1) In univariate analysis, non-French nationality, lower educational level, no health insurance coverage, and no previous HIV testing were associated with a lack of knowledge of HIV transmission routes. In multivariate analysis, all four factors remained significantly associated with a greater lack of knowledge of HIV transmission routes: non-French nationality (aOR, 2.06, 95\% CI, 1.13 to 3.76), a low educational level (aOR, 6.58, 95\% CI, 3.59 to 12.06 ) or a middle school level (aOR, 1.94, 95\% CI, 1.07 to 3.52 ), no health insurance coverage (aOR, $2.53,95 \%$ $\mathrm{CI}, 1.39$ to 4.59 ), and no previous HIV testing (aOR, $2.44,95 \% \mathrm{CI}, 1.40$ to 4.26$)$.

2) In univariate analysis, false beliefs on $H I V$ transmission were associated with age, activity status, educational level, health insurance coverage, sexual orientation and previous HIV testing. In multivariate analysis, six factors were retained by the stepwise selection procedure and four factors remained significantly associated with false beliefs on HIV transmission: age, educational level, sexual orientation and previous HIV testing. Patients under 35 years old were more likely to have false beliefs. The risk of false beliefs increased as the educational level decreased. Men who had sex exclusively with women were more likely to have false beliefs on HIV transmission (aOR, 1.55, 95\% CI, 1.19 to 2.03) compared with MSM. No difference was found among women. No previous HIV testing (aOR, 1.52, 95\% CI, 1.18 to 1.97 ) and only one previous HIV test (aOR, 1.40, 95\% CI, 1.11 to 1.78 ) were significantly associated with false beliefs on HIV transmission in multivariate analysis.

\section{Discussion}

Among patients consulting in a free screening center for HIV and STIs in Paris, only 3.6\% had a lack of knowledge of HIV transmission routes, i.e. they did not know that HIV could be transmitted by unprotected sexual intercourse and/or by sharing used needles. However, three of 10 patients reported at least one act of unprotected sexual intercourse with a partner of unknown HIV status, and almost half did not know that post-exposure prophylaxis is an emergency treatment. Moreover, 36\%

Table 2 Knowledge of HIV transmission and post-exposure prophylaxis $(n=2002)$

\begin{tabular}{|c|c|c|}
\hline & Correct answer & $\%$ Incorrect $^{\mathrm{a}}$ answer $(\mathrm{n})$ \\
\hline \multicolumn{3}{|l|}{ HIV transmission is possible from ... } \\
\hline unprotected sexual intercourse ${ }^{b}$ & Yes & $1.2(24)$ \\
\hline sharing used needles ${ }^{b}$ & Yes & $3.3(66)$ \\
\hline sharing a drink with an infected person ${ }^{c}$ & No & $9.7(195)$ \\
\hline kissing an infected person ${ }^{c}$ & No & $17.6(353)$ \\
\hline using public toilets $^{c}$ & No & $27.5(550)$ \\
\hline \multicolumn{3}{|l|}{ Post-exposure prophylaxis (PEP) consists of ... } \\
\hline taking emergency treatment as soon as possible after risky intercourse & Yes & $55.6(1113)$ \\
\hline
\end{tabular}

ancorrect answers included "Don't know"

${ }^{\mathrm{b}}$ statement taken into account for the Lack of knowledge of HIV transmission routes outcome

cstatement taken into account for the False beliefs on HIV transmission outcome 


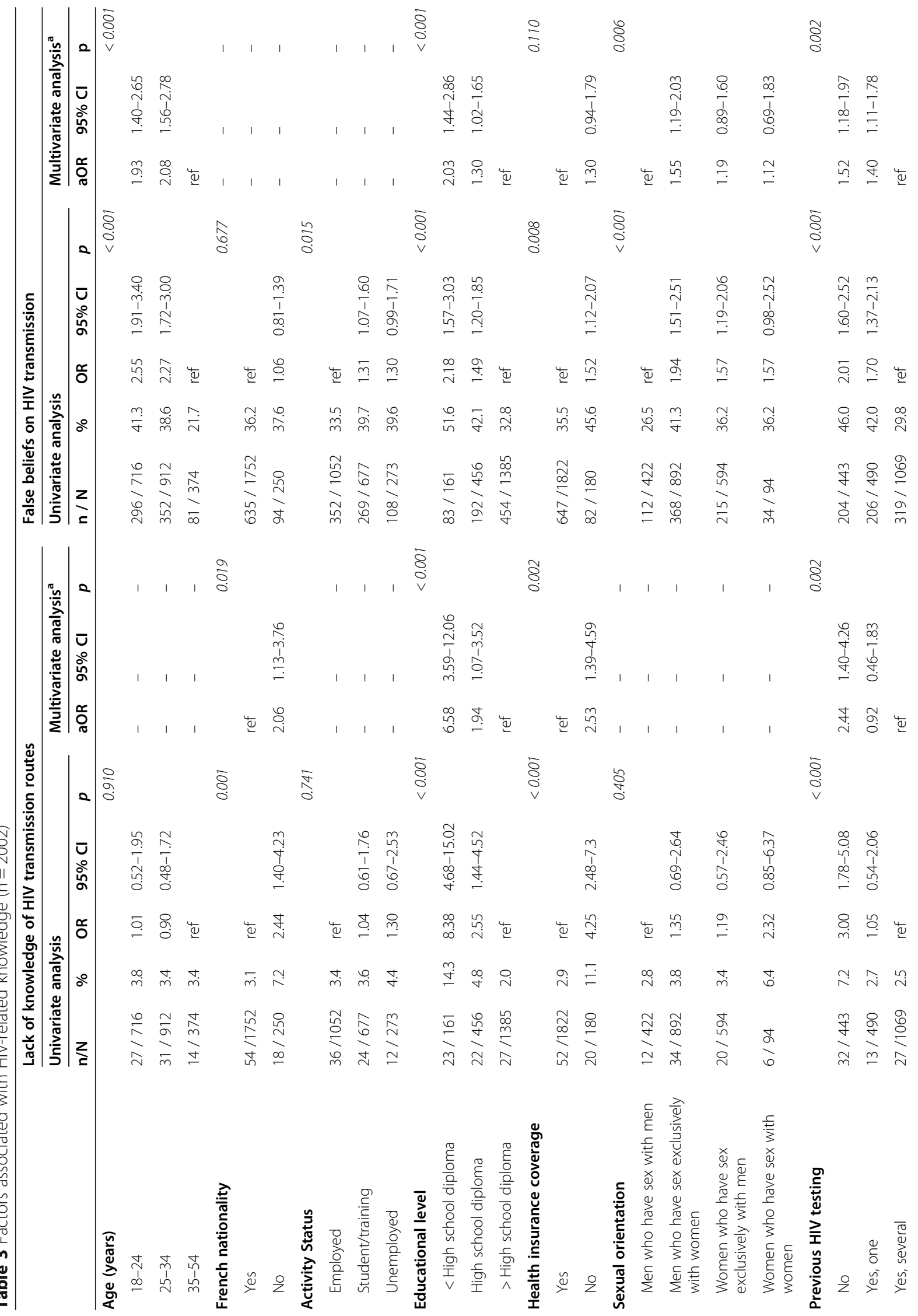




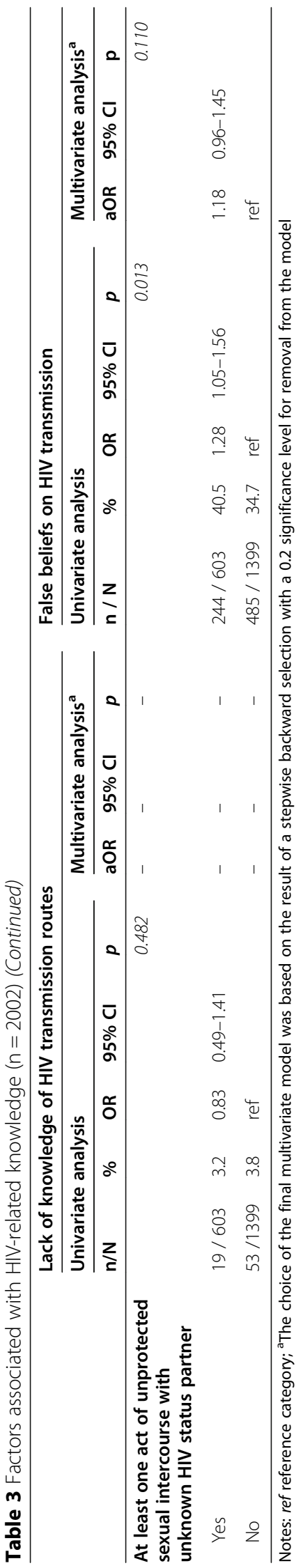


of patients had false beliefs on HIV transmission. Socially disadvantaged patients and those with no previous HIV testing were more likely to have both insufficient knowledge and false beliefs regarding HIV transmission.

Our results observed in a population of patients consulting in a free screening center for HIV and STIs can be compared with the French general population only by using the most recent French national survey, the KABP France Group study (Knowledge, Attitudes, Beliefs and Practices), carried out in 2010 nearly one decade before our study [18]. The lack of knowledge about HIV transmission by sharing used needles was greater among patients of our free screening center than in the French general population in 2010. A few more recent studies have reported in detail on HIV-related knowledge [12, 19]. For instance, a Serbian study conducted in 2013-2014 among 1017 students reported that $2.7 \%$ of students did not know that HIV transmission is possible via sexual intercourse and $8.7 \%$ via intravenous drug equipment [12]. These studies reported higher levels of unawareness than ours, but comparison is limited due to the difference in settings. Taken together, these studies highlight the need for better targeting of prevention and education campaigns [20]. The spread of efficient treatments has changed the social representations of HIV/AIDS from 'deadly' to 'chronic' [21]. Change in representations may have reduced the fear of HIV and the attention paid to prevention campaigns.

More than one third of our study population had false beliefs on HIV transmission. The main false belief was that HIV transmission is possible by using public toilets (27.5\% [95\% CI, 25.5 to 29.4]). This false belief may have increased over the last decade in France, as this proportion was much lower in the 2010 French survey (16.8\% [95\% CI, 15.9 to 17.7]) [22]. Transmission of HIV using public toilets seems to be a common false belief that is largely held worldwide, as it has also been reported in Poland in a national opinion survey among adults (23\%) [23], in Egypt among dental students (38\%) [24], and in Korea among adolescents aged 16-18 years (40.5\%) [25]. In our study, $17.6 \%$ also had false beliefs about HIV transmission through kissing an infected person and 9.7\% through sharing a drink. These false beliefs are also observed in other populations, sometimes at a higher level [7, 26]. A study in the Kingdom of Saudi Arabia among young medical students showed that 52\% thought HIV transmission was possible through a deep kiss and $18.6 \%$ through sharing a glass of water [26]. An American study among Hispanic men on college campuses observed that $41 \%$ thought HIV transmission was possible by kissing and $22 \%$ by sharing a glass [7]. The same false beliefs thus seem to be widely shared among populations of very different social and cultural backgrounds worldwide, even if the levels of these false beliefs are highly variable from one population to another.

False beliefs about HIV could be perceived as a less acute issue than lack of knowledge of HIV transmission routes. Indeed, false beliefs do not lead to HIV infection. However, such false beliefs may lead to discrimination and negative attitudes towards people living with HIV, for example avoidance of such persons [19]. Therefore, false beliefs should be considered as an important issue that needs to be addressed, especially among young people [20]. In a French survey conducted in 2019 in young people $15-24$ years old, $23 \%$ felt poorly informed, compared with only $11 \%$ in 2009 [27]. Prevention and education campaigns should focus more specifically on young people [20].

Patients who had one or several previous HIV screening tests were less likely to have lack of knowledge of HIV transmission routes and false beliefs on HIV transmission. Some previous studies have reported an association between HIV knowledge and previous HIV testing $[14,28]$. Participants who had undergone HIV testing were more likely to have a higher HIV knowledge score and a lower stigma score towards persons living with HIV than those who had not tested for $\operatorname{HIV}[7,28]$. A cross-sectional Chinese study among rural migrants showed that women with little HIV knowledge and low awareness regarding HIV risk were less willing to use voluntary counseling and testing [14]. An American study among adolescent MSM reported that those who had correct HIV knowledge were more likely to be tested for HIV [29]. Furthermore, 75.4\% of MSM tested had previously spoken to a doctor about HIV testing compared with only $10.8 \%$ of those who had not had such conversations. On the other hand, a study conducted among students (18-24 years) in Tbilisi, Georgia, found that having had a HIV test was associated with not having a stigmatizing attitude towards HIV [30]. It is therefore not easy to interpret such an association between HIV knowledge and previous HIV testing. Possibly, patients who are more aware about HIV/STI may be more likely to come for STI screening, or screening may have been an opportunity to improve their knowledge. More studies, in particular prospective studies, are needed to clarify the relationship between HIV knowledge and HIV testing.

In our study, patients with a low educational level were significantly more likely to have lack of knowledge of HIV transmission routes and false beliefs on HIV transmission. This patient profile with low educational level has already been reported to be associated with a low level of HIV knowledge in previous studies [28, 31]. A Bangladeshi study among 12,593 married women found that a higher educational level was a major factor 
influencing a high score of HIV knowledge and awareness. Furthermore, wealth index and access to mass media were also associated with HIV knowledge and awareness [31]. However, these studies were conducted in developing countries, limiting comparison with our results.

In our study, sexual orientation was significantly associated with false beliefs on HIV transmission but not with lack of knowledge of HIV transmission routes. MSM had significantly less false beliefs on HIV transmission than men who have sex exclusively with women. This could be due to better targeted outreach and information campaigns to at-risk populations by community-based organizations [32]. The absence of a significant association between knowledge about HIV transmission and sexual orientation may be due to a lack of statistical power (only 72 patients had a lack of knowledge of HIV transmission routes). However, previous studies reported mixed results regarding an association between sexual orientation and HIV knowledge. Some studies found that MSM were aware of HIV transmission risks [15], but HIV knowledge may vary depending on how MSM self-identify [16]. Furthermore, a study conducted among Thai students reported that being homosexual or bisexual was associated with false perception of low HIV risk [33].

Despite a high level of knowledge regarding HIV transmission routes, our study revealed the need to improve knowledge about post-exposure prophylaxis (PEP). Only $44 \%$ of our study population knew that PEP is an emergency treatment to prevent HIV infection, although PEP has existed in France for more than 20 years (since 1998). Unawareness of PEP could lead to missed opportunities to avoid HIV infection. This lack of knowledge about PEP was reported in previous studies with variable levels of awareness according to the settings and populations. A study conducted among 400 participants who attended a clinic in Jerusalem for HIV testing reported lower awareness of PEP, with only $24 \%$ of participants being aware that the time window for effective PEP is $72 \mathrm{~h}$ [34]. In a South African study of 169 medical university students, only $28 \%$ reported that PEP can be used to prevent HIV infection [35]. Conversely, an American survey of 529 respondents in 2016-2017 reported a higher level of awareness, with $59 \%$ of participants being aware of PEP [32]. This American study pointed out significant differences of awareness among the three key populations studied, non-white young MSM, transgender women and non-white cisgender women, and reported a very high level of awareness among MSM (80\%). The possibility of pre-exposure prophylaxis (PrEP) to prevent HIV transmission should not mask the role of PEP. For patients who are not candidates for PrEP due to infrequent HIV exposure or a lack of anticipation of sexual risk behavior, PEP remains an effective prevention tool to reduce HIV infections.

\section{Limitations and strengths of the study}

This was a large study with a population of 2002 patients and a high questionnaire participation rate of $65 \%$. It has, however, some limitations. Firstly, the questionnaire was only available in French and on a computer. The eligible population thus included only French-speaking patients, which could create a selection bias due to the language barrier. Moreover, the questionnaire was selfadministered on a computer and it cannot be excluded that some patients did not feel comfortable with computer tools. This hypothesis is coherent with the slightly older age of non-participants in this study who may be less skilled with computers (mean age was 33.2 for nonparticipants vs 28.6 for participants) and the significant association between age and participation $(p<0.001)$. However, sexual behaviors and practices are sensitive data that are difficult to collect and self-reported data by computer could be a more efficient tool than face-toface contact in order to reduce social desirability bias and improve data quality [36].

Secondly, the small number of patients who had a lack of knowledge of HIV transmission routes $(n=72)$ is an encouraging result, but restricted the study's statistical power to explore associated factors in multivariate analysis. Lastly, the generalizability of the findings may be limited by the single-center design of our study. It would be interesting to carry out a similar study in other free HIV and STI screening centers in France.

\section{Conclusions}

This study found that people who attended a free HIV and STI screening center were well aware of the main HIV transmission routes. However, false beliefs persist and could generate stigma towards people living with HIV. Our study highlights the fact that more than half of patients had insufficient knowledge about PEP. Prevention messages must focus on PEP and its availability should be facilitated. In addition to conventional PEP, an on-demand PEP called post-exposure prophylaxis-inpocket (PIP) may be a useful strategy to prevent HIV $[37,38]$. In order to reduce the HIV epidemic, people must know and use the combination of prevention tools that are available. Our results suggest that there is a need to improve awareness of HIV testing and prevention strategies and also to improve HIV-related knowledge, particularly among disadvantaged people. In addition to national prevention and information campaigns, free HIV and STI screening centers have a role to play in promoting sexual health, as screening may be a valuable opportunity to upgrade patients' knowledge of HIV prevention tools and transmission routes. 


\section{Abbreviations}

Cl: Confidence interval; HIV: Human immunodeficiency virus; MSM: Men who have sex with men; PEP: Post-exposure prophylaxis; PrEP: Pre-exposure prophylaxis; STI: Sexually transmitted infection

\section{Supplementary Information}

The online version contains supplementary material available at https://doi. org/10.1186/s12889-021-10547-9

Additional file 1. Self-administered questionnaire (English language version).

Additional file 2. Prevalence of sexually transmitted infections (STIS) tested $(n=2002)$.

\section{Acknowledgements}

The authors are grateful to Fabienne Vereecke, reception agent at CeGIDD, and to patients for their participation. We also thank Nina Crowte for language assistance.

\section{Availability of date and materials}

The datasets used and/or analyzed during the current study are available from the corresponding author on reasonable request.

\section{Authors' contributions}

CD conducted data analysis, interpretation of data and drafted the manuscript. ELR designed the study, participated in interpretation of data and writing, and reviewed the manuscript. PP designed the study, participated in interpretation of data and reviewed the manuscript. CS designed the study and reviewed the manuscript. PT designed the study, participated in analysis, interpretation of data and writing, and reviewed the manuscript. All authors read and approved the final manuscript.

\section{Funding}

Not applicable.

\section{Declarations}

\section{Ethics approval and consent to participate}

This study is based on anonymized patients' medical data, including a selfadministered questionnaire used in routine care. Completion of the selfadministered questionnaire was proposed only to patients who understood written French, by the reception agent (verbal information) before the consultation. Patients were informed that completion of the self-administered questionnaire was optional and that non-participation would not affect care. Moreover, patients were informed by poster in the center and on the welcome page of the self-administered questionnaire of their right to object to the use of their data for research purposes (written information). This procedure complies with French law, as observational studies conducted on previously collected data require individual information and absence of patient objection (no explicit consent is required). Use of these data for research received institutional review board approval from the French Data Protection Authority (authorization CNIL no. 2005208 v0). This procedure complies with the European General Data Protection Regulation and this study has been declared to the AP-HP (Paris hospitals) Data Protection Office (no. 20190409164510)

\section{Consent for publication}

Not applicable.

\section{Competing interests}

The authors declare that they have no competing interests.

\section{Author details}

'Service de Santé Publique, Hôpitaux Lariboisière - Fernand-Widal, AP-HP Nord, F-75010 Paris, France. ${ }^{2}$ Institut National d'Etudes Démographiques (Ined), F-93322 Aubervilliers, France. ${ }^{3}$ Université Paris-Saclay, UVSQ, Inserm, CESP, F94807 Villejuif, France. ${ }^{4}$ CeGIDD, Hôpitaux Lariboisière Fernand-Widal, AP-HP Nord, F-75010 Paris, France.
Received: 12 June 2020 Accepted: 3 March 2021

Published online: 12 March 2021

\section{References}

1. WHO WHO: Fact sheet HIV/AIDS. Available from: https:/www.who.int/newsroom/fact-sheets/detail/hiv-aids (last access on 13 Feb 2020). 2018.

2. UNAIDS: Data 2019. Available from: https://www.unaids.org/sites/default/ files/media_asset/2019-UNAIDS-data_en.pdf (last access on 13 Feb 2020). 2019.

3. UNAIDS: France. Country Factsheets. Available from: https://www.unaids. org/en/regionscountries/countries/france (last access on 13 Feb 2020). 2018

4. Cazein F, Sommen C, Pillonel J, Bruyan M, Ramus C, Pichon P, et al. HIV screening activity and circumstances of new HIV diagnoses, France 2018. Bull Epidemiol Hebd. 2019;31*32:615-24.

5. Kurth $\mathrm{AE}_{1}$ Celum $\mathrm{C}$, Baeten JM, Vermund $\mathrm{SH}$, Wasserheit JN. Combination HIV prevention: significance, challenges, and opportunities. Curr HIV/AIDS Rep. 2011;8(1):62-72.

6. Beltzer N, Saboni L, Sauvage C, Lydie N, Semaille C, Warszawski J, et al. An 18-year follow-up of HIV knowledge, risk perception, and practices in young adults. AIDS. 2013:27(6):1011-9.

7. Fenkl EA, Gracia Jones S, Orta R. Young Hispanic Men's HIV and STI knowledge, attitudes, beliefs, and behaviors. Hispanic Health Care Int. 2016; 14(3):109-15.

8. Mazzitelli M, Carida G, Scigliano C, Vallone MC, Pirro F, Lombardo MR, et al. Knowledge of HIV infection and transmission: a knowledge, attitudes, beliefs and practices (KABP) survey among a sample of students at the "magna Graecia", University of Catanzaro. Annali dell'Istituto superiore di sanita. 2016:52(4):530-5.

9. Othero DM, Aduma P, Opil CO. Knowledge, attitudes and sexual practices of university students for advancing peer HIV education. East Afr Med J. 2009; 86(1):11-5.

10. Hlavinkova L, Mentel A, Kollarova J, Kristufkova Z. Effectiveness of a prevention campaign on HIV/AIDS knowledge among adolescents in eastern Slovakia. Int J Public Health. 2014;59(6):905-11.

11. Arya M, Amspoker AB, Lalani N, Patuwo B, Kallen M, Street R, et al. HIV testing beliefs in a predominantly Hispanic community health center during the routine HIV testing era: does English language ability matter? AIDS Patient Care STDS. 2013;27(1):38-44.

12. Milic M, Dotlic J, Stevanovic J, Parlic M, Mitic K, Nicholson D, et al. Relevance of students' demographic characteristics, sources of information and personal attitudes towards HIV testing for HIV knowledge: evidence from a post-conflict setting. J Biosoc Sci. 2021;53(1):1-19.

13. Teva I, de Araujo LF, de la Paz BM. Knowledge and concern about STIS/HIV and Sociodemographic variables associated with getting tested for HIV among the general population in Spain. J Psychol. 2018;152(5):290-303.

14. Zhang T, Zhang J, Gao M, He N, Detels R. Knowledge, attitudes and practices of voluntary HIV counselling and testing among rural migrants in Central China: a cross-sectional study. Eur J Public Health. 2012;22(2):192-7.

15. Nodin N, Leal IP, Carballo-Dieguez A. HIV knowledge and related sexual practices among Portuguese men who have sex with men. Cad Saude Publica. 2014:30(11):2423-32.

16. Bowring A, van Gemert C, Vongsaiya K, Hughes C, Sihavong A,

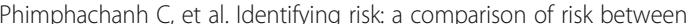
heterosexual-identifying bisexual men and other bisexual men in Vientiane, Laos. AIDS Educ Prev. 2014;26(2):109-21.

17. Denison JA, O'Reilly KR, Schmid GP, Kennedy CE, Sweat MD. HIV voluntary counseling and testing and behavioral risk reduction in developing countries: a meta-analysis, 1990--2005. AIDS Behav. 2008:12(3):363-73.

18. Brouard C, Gautier A, Saboni L, Jestin C, Semaille C, Beltzer N, et al. Hepatitis $\mathrm{B}$ knowledge, perceptions and practices in the French general population: the room for improvement. BMC Public Health. 2013;13:576.

19. Platten M, Pham HN, Nguyen HV, Nguyen NT, Le GM. Knowledge of HIV and factors associated with attitudes towards HIV among final-year medical students at Hanoi medical university in Vietnam. BMC Public Health. 2014;14:265

20. Labra O, Lacasse A, Gingras-Lacroix G. Attitudes et connaissances d'étudiants universitaires à l'égard du VIH-sida. Serv Soc. 2017;63(2):1-20

21. Labra O. Social representations of HIV/AIDS in mass media: some important lessons for caregivers. Int Soc Work. 2015;58(2):238-48. 
22. Saboni L, Beltzer N, group KF. HIV knowledge, attitude, beliefs, and practices in France from 1992 to 2010. KABP, ANRS-ORS-Inpes- IReSP-DGS survey. Bull Epidemiol Hebd. 2012;46*47:525-9.

23. Danziger R. Discrimination against people with HIV and AIDS in Poland. Bmi. 1994;308(6937):1145-7.

24. Abou El Fadl RK, Abdelmoety A, Farahat Z, Hussein MA. Assessing the levels of HIV-related knowledge and attitudes toward HIV-infected patients among undergraduate dental students: a cross-sectional study. Hiv/Aids. 2019;11:83-92

25. Sohn A, Park S. HIV/AIDS knowledge, stigmatizing attitudes, and related behaviors and factors that affect stigmatizing attitudes against HIV/AIDS among Korean adolescents. Osong Public Health Res Perspect. 2012;3(1):24-30.

26. Alawad M, Alturki A, Aldoghayyim A, Alrobaee A, Alsoghair M. Knowledge, attitudes, and beliefs about HIV/AIDS and people living with HIV among medical students at Qassim University in Saudi Arabia. Int J Health Sci. 2019; 13(5):22-30

27. Cour des comptes: La prévention et la prise en charge du VIH. https://www. ccomptes.fr/system/files/2019-07/20190703-rapport-prevention-prise-en-cha rge-VIH.pdf. In.; 2019: Communication à la Commission des affaires sociales du Sénat.

28. Mall S, Middelkoop K, Mark D, Wood R, Bekker LG. Changing patterns in HIV/AIDS stigma and uptake of voluntary counselling and testing services: the results of two consecutive community surveys conducted in the Western cape, South Africa. AIDS Care. 2013;25(2):194-201.

29. Mustanski B, Moskowitz DA, Moran KO, Rendina HJ, Newcomb ME, Macapagal K. Factors Associated With HIV Testing in Teenage Men WhoHave Sex With Men. Pediatrics. 2020;145(3):e2019232.

30. Djibuti M, Zurashvili T, Kasrashvili T, Berg CJ. Factors associated with HIV counseling and testing behavior among undergraduates of universities and vocational technical training schools in Tbilisi, Georgia. BMC Public Health. 2015;15:427.

31. Haque MA, Hossain MSN, Chowdhury MAB, Uddin MJ. Factors associated with knowledge and awareness of HIV/AIDS among married women in Bangladesh: evidence from a nationally representative survey. SAHARA J J Soc Aspects HIV/AIDS Res Alliance. 2018;15(1):121-7.

32. Koblin BA, Usher D, Nandi V, Tieu HV, Bravo E, Lucy D, et al. Post-exposure prophylaxis awareness, knowledge, access and use among three populations in new York City, 2016-17. AIDS Behav. 2018;22(8):2718-32.

33. Khawcharoenporn T, Chunloy K, Apisarnthanarak A. HIV knowledge, risk perception and pre-exposure prophylaxis interest among Thai university students. Int J STD AIDS. 2015;26(14):1007-16.

34. Leshin D, Olshtain-Pops K, Moses A, Elinav H. Limited awareness of the effective timing of HIV post-exposure prophylaxis among people with highrisk exposure to HIV. Eur J Clin Microbiol Infect Dis. 2019;38(4):779-84.

35. Ncube NB, Meintjes WA, Chola L. Knowledge and attitudes of nonoccupational HIV post-exposure prophylaxis amongst first- and second-year medical students at Stellenbosch University in South Africa. Afr J Prim Health Care Fam Med. 2014;6(1):E1-9.

36. McCallum EB, Peterson ZD. Investigating the impact of inquiry mode on self-reported sexual behavior: theoretical considerations and review of the literature. J Sex Res. 2012;49(2-3):212-26.

37. Heendeniya A, Bogoch II. HIV prevention with post-exposure prophylaxis-inpocket. Lancet Public Health. 2019;4(10):e494.

38. Tumarkin E, Heendeniya A, Murphy P, Placido T, Tan DHS, Bogoch II. Brief report: HIV Postexposure prophylaxis-in-pocket ("PIP") for individuals with low-frequency, high-risk HIV exposures. J Acquir Immune Defic Syndr. 2018; 78(1):20-2.

\section{Publisher's Note}

Springer Nature remains neutral with regard to jurisdictional claims in published maps and institutional affiliations.

Ready to submit your research? Choose BMC and benefit from:

- fast, convenient online submission

- thorough peer review by experienced researchers in your field

- rapid publication on acceptance

- support for research data, including large and complex data types

- gold Open Access which fosters wider collaboration and increased citations

- maximum visibility for your research: over $100 \mathrm{M}$ website views per year

At BMC, research is always in progress.

Learn more biomedcentral.com/submissions 